\title{
Antinociceptive and Anti-inflammatory Effects of the Hydroalcoholic Fraction from Leaves of Cenostigma macrophyllum Tul. var. acuminata Teles Freire (Leguminosae) in Rodents
} \author{
FA Oliveira ${ }^{1}$ and FRC Almeida ${ }^{1}$ \\ ${ }^{1}$ Medicinal Plants Research Center, Federal University of Piauí, Brazil \\ ${ }^{2}$ Department of Chemistry, Federal University of Piauí, Brazil \\ ${ }^{3}$ Department of Pathology, São Marcos Hospital, Brazil
}

MF Cavalcanti ${ }^{1 *}$, HB Fernandes ${ }^{1}$, SS Pereira ${ }^{1}$, CA Piauilino ${ }^{1}$, CLS Costa ${ }^{2}$, MH Chaves ${ }^{2}$, JO Ibiapina ${ }^{3}$, RB Marques ${ }^{1}$,

Submission: August 14,2017; Published: August 21, 2017

*Corresponding author: MF Cavalcanti, Medicinal Research Center, Federal University of Piauí, Av. Nossa Senhora de Fátima s/n, 64049-550

Teresina, Brazil, Tel: +55 863215 5872; Fax: +55 863125 5560; Email: maurofurtado@uol.com.br

Abstract

Introduction: Cenostigma macrophyllum Tul. var. acuminata Teles Freire (Leguminosae) is locally known as "caneleiro" and its barks, leaves and flowers are used in folk medicine against stomach disorders and abdominal pain. HPLC analysis of hydroalcoholic fraction from leaves $(\mathrm{Cm}$ HAF) indicated two biflavones as main constituents: agathisflavone and amentoflavone.

Purpose: To investigate antinociceptive and anti-inflammatory/antiarthritic effects of $\mathrm{Cm}$-HAF in animal models.

Materials and Methods: We used male Swiss mice (25-30 g) and female Wistar rats (150-210 g). Acute antinociception was evaluated using formalin, capsaicin and glutamate tests. Complete Freund's adjuvant (CFA)-induced monoathritic rats were treated with $\mathrm{Cm}$-HAF (50, 100 and $200 \mathrm{mg} / \mathrm{kg}$ p.o.) for 15 days and evaluated for acute D (0-1), sub-acute D (3-7) and chronic D (10-14) anti-inflammatory (paw edema) and antinociceptive effects (mechanical nociception). Histological evaluation of paws, blood urea nitrogen (BUN), creatinine and alanine-amino transferase (ALT) dosage, total body weight variation, wet weight of kidneys and liver and macroscopical evaluation of gastric mucosae were performed on D (14).

Results: $\mathrm{Cm}$-HAF produced significant antinociceptive effect in capsaicin, glutamate tests and in the late phase of formalin test. CFA-induced monoarthritic rats treated with $\mathrm{Cm}$-HAF (50, 100 and $200 \mathrm{mg} / \mathrm{kg}$ p.o.) showed no significant differences on paw diameter or histological evaluation, but showed a significant antinociception ( $\mathrm{Cm}$-HAF 100 and $200 \mathrm{mg} / \mathrm{kg}$ p.o.) similar to indomethacin (IND - $3 \mathrm{mg} / \mathrm{kg}$ p.o.).

Conclusion: $\mathrm{Cm}$-HAF has antinociceptive but not antiedematogenic/antiarthritic effects in rodents. These results contribute to the pharmacological knowledge of this species and support its ethnomedical use.

Keywords: Cenostigma macrophyllum; Antinociceptive; Anti-inflammatory; Complete Freund's adjuvant arthritis; Biflavones; Amentoflavone; Agathisflavone

\section{Introduction}

Rheumatoid arthritis (RA) is a chronic systemic inflammatory disease that causes premature mortality, disability, chronic pain and compromises quality of life. RA's prevalence ranges from $0.5-1.0 \%$ Silman [1]. Advances in the treatment of RA in the past decade have been achieved mainly by using combinations of different conventional and biologic DMARDs (Disease-modifying antirheumatic drug) Feist \& Burmester [2]. Unfortunately, this promising and expensive arsenal of drugs is not yet available for most of people, especially in developing countries. The frontline drugs for RA treatment still remains the nonsteroidal antiinflammatory drugs (NSAIDs), steroids and traditional DMARDS, with all well known undesirable effects such as gastrointestinal ulcers, osteoporosis, diabetes mellitus and many others Lewis \& Levy [3]. Thus novel approaches with safer and more available drugs are urgently needed. 
Ethnopharmacological and ethnobotanical an investigation has been the main research field of scientists worldwide in order to select medicinal plants. Studies on folk medicine have been a consistent source of anti-inflammatory drugs for decades Norn et al. [4]. Therefore, the use of herbs with therapeutic potential in inflammatory arthritis such as RA should be further investigated. Cenostigma macrophyllum Tul. var. acuminata Teles Freire, is a tree that belongs to the family LeguminosaeCaesalpinoideae, commonly known as "caneleiro". It is widely found in North, Midwest and Northeast of Brazil, especially at "cerrado and caatinga" biomes Queiroz [5]. This species has an important role to people of the semiarid northeastern Brazilian region ("caatinga") as an alternative source for cattle feed during the dry season Ribeiro \& Pelacani [6]. Its stem barks, leaves and flowers are used in folk medicine against stomach disorders and intestinal pain Sousa et al. [7].

HPLC analysis of $\mathrm{Cm}$-HAF (hydroalcoholic fraction from leaves of Cenostigma macrophyllum Tul. var. acuminata Teles Freire (Leguminosae)) showed two biflavones as main constituents: amentoflavone and agathisflavone (Figure 1) Viana et al. [8]. Some flavonoids are enzyme inhibitors and antioxidants and have been reported to have anti-inflammatory properties Kim [9]. However, the molecular mechanisms explaining how flavonoids suppress the inflammatory response are not known in detail Southon et al. [10]. The ethanol extract from Cenostigma macrophyllum Tul. var. acuminata Teles Freire leaves has showed antiulcerogenic effect, as well as anti-inflammatory, antioxidant, antinociceptive and antibacterial properties (unpublished results). Interestingly, we had more recent studies about pharmacological activities of Cenostigma macrophyllum.

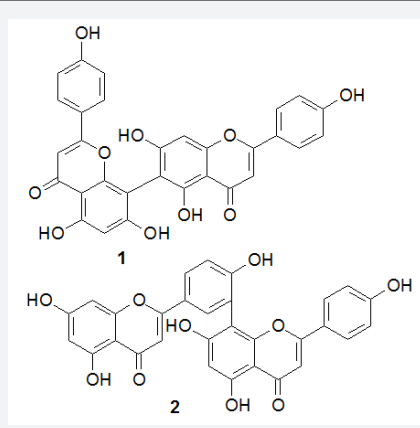

Figure 1: Constituents of $\mathrm{Cm}-\mathrm{HAF}$.

1. Agathisflavone.

2. Amentoflavone.

The first one showed that $\mathrm{Cm}$-HAF apparently had no toxicological effect and provided gastro protection against gastric damage induced by ethanol and ethanol- $\mathrm{HCl}$, isquemia reperfusion injury and cold restraint stress in rodents, which were possibly mediated, in part, by nitric oxide release and $\mathrm{K}_{\text {ATP }}^{+}$ channel opening. This extract also exhibited protection against lesions by ischemia-reperfusion and antioxidant effect, in part, by increase catalase activity Viana et al. [8]. In the last one, ethanol extract $(\mathrm{Cm}$-E.EtOH) and ethyl acetate fraction $(\mathrm{Cm}-\mathrm{F}$.
EtOAc) from stem bark of Cenostigma macrophyllum presented antinociceptive activity in streptozotocin (STZ)-induced diabetic rats. $\mathrm{Cm}$-EtOAc might exert its effect by affecting the opioid system, but nitrergic mechanisms were not detectable Piaulino et al. [11]. Hence, the present study proposes to evaluate the antinociceptive e anti-inflammatory effects of $\mathrm{Cm}$-FHA in animal models of pain and inflammation (arthritis).

\section{Materials and Methods}

\section{Plant Material and Preparation of Fraction}

Leaves of Cenostigma macrophyllum Tul. Var. acuminata Teles Freire were collected from the campus of Federal University of Piaui (UFPI) in July, 2009 and identified in the Biology Department - UFPI and a voucher specimen (no. TEPB 10,374) has been deposited at the Graziela Barroso Herbarium, Brazil. The dried and powdered leaves ( $4.0 \mathrm{~kg}$ ) were submitted to $95 \%$ ethanol extraction in 5 consecutive steps at room temperature. The concentrated ethanol extract, 547g (13.7\%), was suspended in methanol/water (1:2) and extracted with ethyl acetate yielding the aqueous ( $\left.\mathrm{F} . \mathrm{H}_{2} \mathrm{O} ; 154 \mathrm{~g}, 28.2 \%\right)$ and ethyl acetate (F. EtOAc; 384 g, 70.2\%) phases. The latter was concentrated, suspended in methanol/water (9:1) and extracted with hexane producing a hexane (145.9 g, 38.0\%) and a hydroalcoholic fraction (Cm-HAF, 231.0g, 60.2\%).

\section{High-Performance Liquid Chromatography (HPLC) Analysis of $\mathrm{Cm}$-HAF}

Elution was performed with $\mathrm{MeOH} / \mathrm{H}_{2} \mathrm{O}$ (73:27), in an isocratic elution mode, at a flow rate of $1.0 \mathrm{~mL} / \mathrm{min}$, at room temperature $\left(25^{\circ} \mathrm{C}\right)$ and a $30 \mu \mathrm{L}$ injection of $\mathrm{Cm}-\mathrm{HAF}$ at a concentration of $5.0 \mathrm{mg} / \mathrm{mL}$. The chromatograms were monitored at $330 \mathrm{~nm}$. The equipment used was Analytical reversed-phase HPLC, Shimadzu® prominence system (comprising a model LC6AD pump, a manual-sampler, and an SPD-20A UV detector) fitted with a Shim-pack CLC-ODS (M) C18 column (250 mm x 4.6 $\mathrm{mm}, 5 \mu \mathrm{m}$ ), with control and data handling managed by the LC solution software (Figure 2).

\section{Chemicals and Reagents}

Capsaicin, glutamate, dizocilpine (MK801) and tween 80 were obtained from Sigma Chemicals (USA). Complete Freund's Adjuvant $(0.5 \mathrm{mg} / \mathrm{ml}$ of Mycobacterium butyricum) was purchased from DIFCO Laboratories (Detroit, USA) and Morphine was purchased from Cristália Produtos Químicos e Farmacêuticos Ltda. (SP, Brazil). Indomethacin (Indocid $®$ ) was obtained from Merck Sharp \& Dohme Farmacêutica Ltda (SP, Brazil), dexamethasone (Decadron) from Aché Laboratórios Farmacêuticos S.A. (SP, Brazil) and formaldehyde from Dinâmica Química Contemporânea Ltda. (SP, Brazil). Body Urea Nitrogen (BUN), creatinine and alanine aminotransferase (ALT) kits assay from Labtest Diagnóstica (MG, Brazil). Cm-HAF was obtained from our chemist collaborator at Department of Chemistry, UFPI, Teresina, Brazil. 

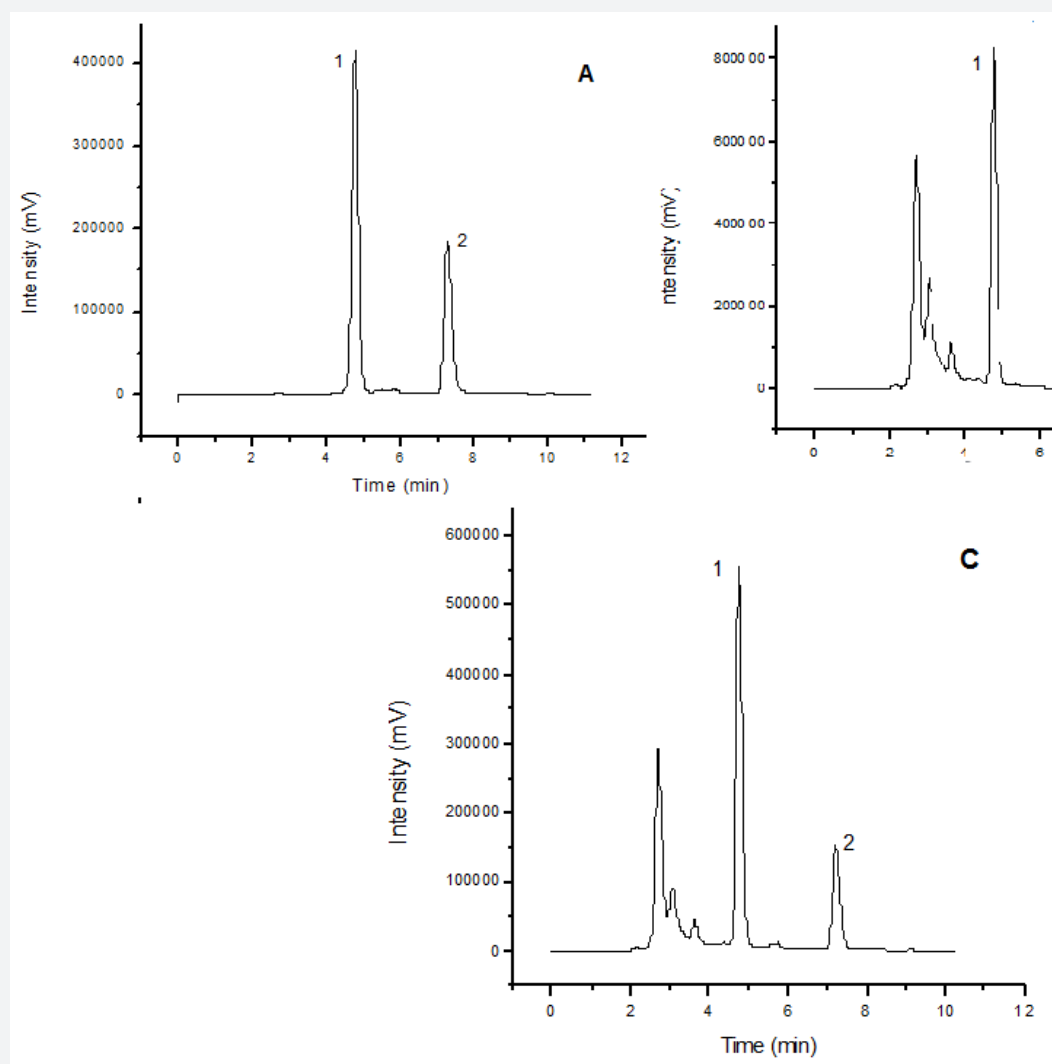

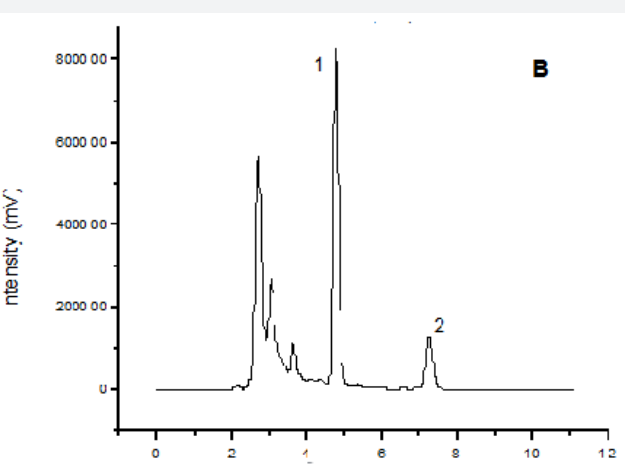

Figure 2:

A. HPLC chromatogram of mixture of Agathisflavone (1) and Amentoflavone (2).

B. HPLC chromatogram obtained from Cm-HAF.

C. HPLC chromatogram obtained from Cm-HAF with co-injection of the mixture of agathisflavone and amentoflavone. The column was $\mathrm{C} 18$ with elution in $\mathrm{MeOH} / \mathrm{H}_{2} \mathrm{O}(73: 27)$ isocratic flow of $1.0 \mathrm{~mL} / \mathrm{min}$

\section{Animals}

Male Swiss mice (20-30 g) and female Wistar rats (180$210 \mathrm{~g}$ ) from NPPM Bioterio of Federal University of Piauí were used. Animals were randomly distributed in the control and test groups with 5-12 animals in each group. They were kept in a temperature-controlled-environment $\left(24^{\circ} \pm 1^{\circ} \mathrm{C}\right)$ under a $12 \mathrm{~h}$ light-dark cycle. Standard laboratory diet and water were freely available. Before each experiment the animals were deprived of food for 18 hours but had free access to drinking water. Experimental protocols were approved by Institutional Committee on Care and Use of Animals for ex $\urcorner$ perimentation UFPI (No.024/09).

\section{Antinociceptive tests}

\section{Formalin test}

After a 15 minutes adaptation period, mice were divided into 5 groups $(n=6-12)$. Four groups were orally given $\mathrm{Cm}$-HAF $(100,200$ and $400 \mathrm{mg} / \mathrm{kg})$, or vehicle $(10 \mathrm{ml} / \mathrm{kg}) 1$ hour before the nociceptive challenge. The positive control group received morphine (5 mg/kg s.c.) $30 \mathrm{~min}$ before the test. The right hind paw was injected with formalin $(20 \mu \mathrm{L}, 2 \%)$ in the intraplantar region. Nociception index was the licking time of the injected paw during the first $5 \mathrm{~min}$ (first phase) and at 15-30 min (second phase) Hunskaar \& Hole [12]; Tjølsen et al. [13].

\section{Capsaicin test}

Mice were divided into 5 groups ( $\mathrm{n}=7-12)$. Afterwards, they were treated with vehicle (10 ml/kg p.o.) or $\mathrm{Cm}-\mathrm{HAF}$ (25, 50 and $100 \mathrm{mg} / \mathrm{kg}$ p.o.) 1 hour before capsaicin injection. The positive control group received morphine ( $5 \mathrm{mg} / \mathrm{kg}$ s.c.) $30 \mathrm{~min}$ before the test. After the adaptation period, $20 \mu \mathrm{l}(2 \mu \mathrm{g} / \mathrm{paw})$ were injected in the intraplantar region of the right hind paw. The animals were observed individually for the 5 following minutes. The time spent licking the injected paw was considered as indicative of nociception Sakurada et al. [14]; Santos \& Calixto [15].

\section{Glutamate-induced nociception}

The procedure was similar to that described by Beirith at al. [16]. Animals were divided into 5 groups $(n=6-12)$ and treated with $\mathrm{Cm}$-HAF $(6.25,12.5$ and $25 \mathrm{mg} / \mathrm{kg}$ p.o.) or vehicle $(10 \mathrm{mg} /$ $\mathrm{kg}$ p.o.) 1 hour before test. The positive control group was treated with MK 801 ( $0.03 \mathrm{mg} / \mathrm{kg}$ i.p.) $30 \mathrm{~min}$ before the test. A volume of $20 \mu$ l of glutamate solution $(10 \mu \mathrm{mol} / \mathrm{paw})$ was injected in the 
ventral surface of the right hind paw. Animals were individually observed from 0 to $15 \mathrm{~min}$. The time spent licking the injected paw was timed with a chronometer and considered as indicative of nociception.

\section{Measurement of Locomotor Activity}

The ambulatory behavior was assessed in the open field test as reported previously Broadhurst [17]. The open field is an acrylic box with transparent walls and black floor (30 x $30 \times 15 \mathrm{~cm}$ ), and its base is divided into 9 equal quadrants. One day before the test, the mice were placed in the arena for an adaptation period. The animals were divided into 3 groups ( $\mathrm{n}=5-7)$ and treated with $\mathrm{Cm}$-HAF (100 mg/kg, p.o.) or vehicle (10 ml/kg p.o.) $60 \mathrm{~min}$ before the test or diazepam ( $4 \mathrm{mg} / \mathrm{kg}$ s.c.) $30 \mathrm{~min}$ before the test and placed individually to the open field. The number of squares crossed with all paws (crossings) was registered during $5 \mathrm{~min}$.

Experimental model of chronic Monoarthritis Induced by Complete Freund's Adjuvant

\section{Induction and Evaluation}

The tail base of female Wistar rats (150-210 g) were sterilized with $70 \%$ alcohol and intradermally injected with $50 \mu \mathrm{L}$ of CFA (Complete Freund's Adjuvant: $0.5 \mathrm{mg} / \mathrm{ml}$ of M. butyricum) using a sterile hypodermic needle. After 21 days, measurement of paw diameter at metatarsal level with a digital paquimeter and assessment of mechanical hyperalgesia with an analgesymeter, based on the method described by Randall \& Sellitto [18] were performed.

This device applies a linearly increasing mechanical force to the dorsum of the hindpaw and the nociceptive threshold was defined as the force $(\mathrm{g})$ at which the rats withdrew their paws. They were randomly divided into 6 groups $(n=6-9)$ and pretreated with vehicle (10 ml/kg p.o.), Cm-HAF (50, 100 and $200 \mathrm{mg} / \mathrm{kg}$ p.o.), indomethacin (IND) (3 mg/kg p.o.) or dexamethasone (DEX) in saline solution (0.4 mg/kg p.o.). Afterwards they received a similar injection of CFA around the right tibio-tarsal joint (booster). This was considered the initial arthritis day $\mathrm{D}(0)$. The treatments were repeated daily from $\mathrm{D}(0)$ to $\mathrm{D}(14)$. Paw diameter (oedema) and withdrawal threshold (inflammatory pain) were evaluated every hour during the next 6 hours after booster injection on $\mathrm{D}(0)$ and once on $\mathrm{D}(1)$ (acute phase); D(3), D(5) and D(7)(sub-acute phase); D(10) and $D(14)$ (chronic phase). The measurements of each arthritic rat parameters were blindly carried out on triplicate by a skilled observer, according to Gomes [19] with modifications.

\section{Histological Evaluation}

The rats were euthanized at the end of the experiment (D(14)) with a sodium thionembutal injection (i.p). All right hind paws and some left hind paws were removed and fixed in $10 \%$ PBS-formalin and then decalcified in formic acid, embedded in paraffin, sectioned at $5 \mu \mathrm{m}$ and stained with haematoxylin and eosin (HE) and were blindly examined under light microscopy by a pathologist, regarding the treatment groups. The severity of arthritis was evaluated by scoring the following observations: grading of cellular infiltration (polymorph nuclear cells or lymphocytes), alteration of tissue architecture, tissue edema and synovial membrane thickening. A four-grade score was used, varying from 0 (no changes), 1 (mild changes), 2 (moderate changes), and 3 (severe changes) Beehler et al. [20]. The median of the scores was used to express the severity of arthritis.

Effect of chronic treatment with $\mathrm{Cm}$-HAF in blood urea nitrogen (BUN), creatinine, alanine-amino transferase (ALT), total body weight, wet weight of kidneys and liver and macroscopical evaluation of gastric mucosae in CFAinduced monoarthritic rats. After the arthritis assessment on $\mathrm{D}(14)$, rats were weighed and deeply anesthetized with sodium tionembutal ( $80 \mathrm{mg} / \mathrm{kg}$ i.p.). Immediately after, blood from inferior vena cava was collected for biochemical analysis: BUN, creatinine and ALT. Kidneys and liver were removed for wet weighing (weighted for $100 \mathrm{~g} /$ animal) and stomachs were then removed, opened along the greater curvature, and rinsed with physiological saline. Afterwards, they were mounted on a paraffin plate to minimize mucosal folding.

The gastric mucosae was carefully examined macroscopically, and blinded scored by a skilled observer. The gastric mucosal damage was assessed by the following parameters: loss of folds (1 point), discoloration (1 point), edema (1 point), hemorrhage ( 1 point), petechiae number $\leq 10$ ( 2 points), petechiae number $>10$ ( 3 points), ulcers or erosions $\leq 1 \mathrm{~mm}$ (number $\mathrm{x} 2$ ), ulcers or erosions $>1 \mathrm{~mm}$ (number $\mathrm{x} 3$ ) and perforated ulcers (number $x$ 4), according to Szabo [21] with modifications. The median of the scores was used to express the severity of gastric mucosae damage. The total body weight variation was determined from the difference between D (0) and D (14).

\section{Statistical analysis}

The results were expressed as mean \pm S.E.M and analyzed by one-way or two-way ANOVA followed by post hoc Bonferroni test. Macroscopical and microscopical evaluations were expressed as median of scores and analyzed by Kruskal-Wallis one-way ANOVA. Differences between groups were considered significant when $p<0.05$ (Graph Pad Prism ${ }^{\mathrm{TM}}$ software version 5.0).

\section{Results}

\section{Formalin Test}

Cm-HAF (200 and $400 \mathrm{mg} / \mathrm{kg}$ p.o.) significantly reduced the time during which the animals licked their stimulated paw. However, the reduction only took place in the second phase, when compared with vehicle $(\mathrm{Cm}-\mathrm{HAF} 200 \mathrm{mg} / \mathrm{kg}$ : $63.36 \pm 3.76$ $\mathrm{s}, \mathrm{Cm}$-HAF $400 \mathrm{mg} / \mathrm{kg}: 65.10 \pm 4.12 \mathrm{~s}$ and vehicle $88.79 \pm 5.78$ s). This corresponds to a 28.64 and $26.68 \%$ time reduction, respectively (Figure 3 ). 


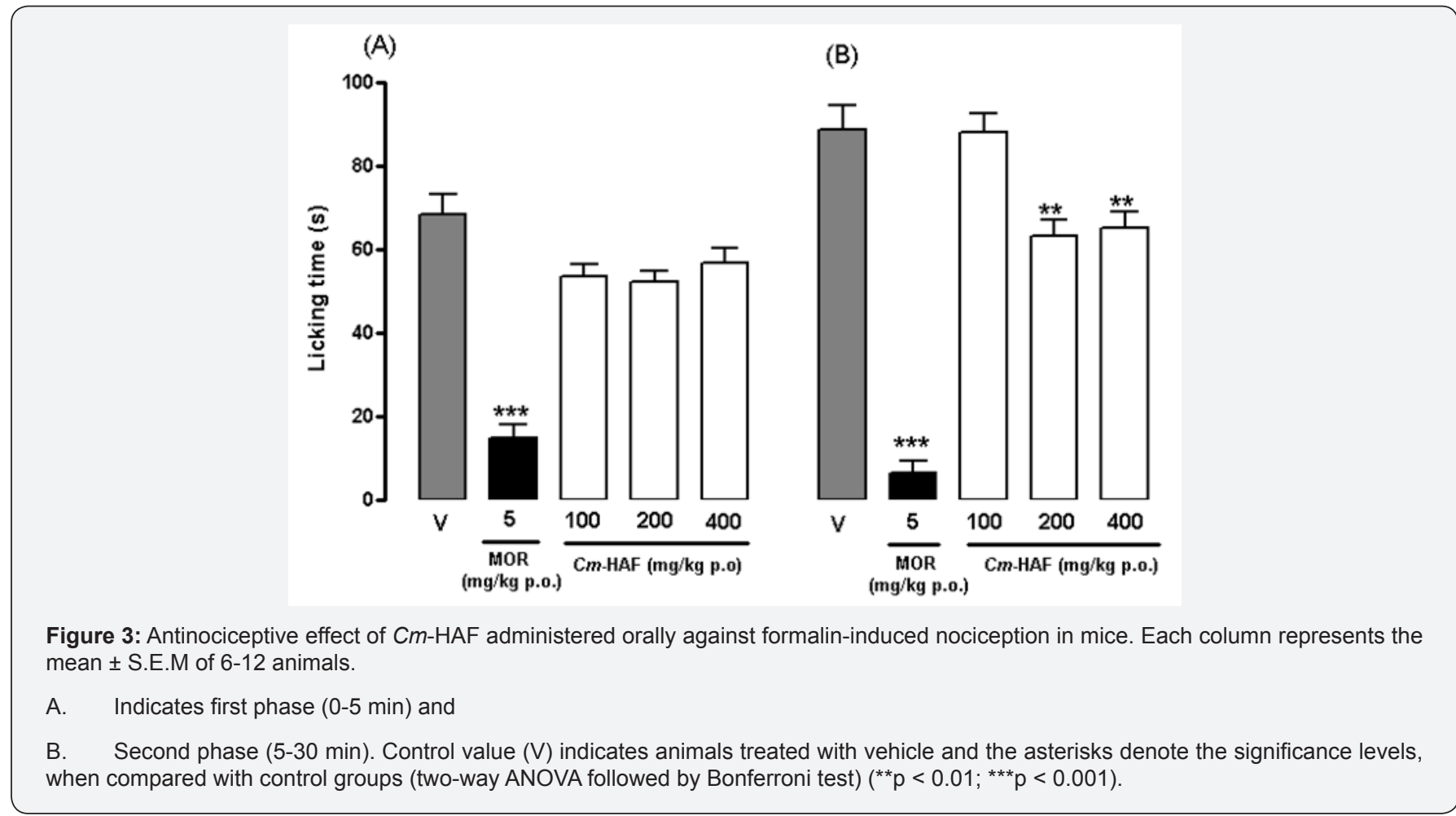

\section{Capsaicin Test}

$\mathrm{Cm}$-HAF (50 and $100 \mathrm{mg} / \mathrm{kg}$ p.o.) significantly reduced the response time of the animals when compared with vehicle $(\mathrm{Cm}$ HAF 50 mg/kg: $23.73 \pm 1.62$ s; Cm-HAF 100 mg/kg: $21.56 \pm 1.07$ $\mathrm{s}$ and vehicle $36.04 \pm 1.99 \mathrm{~s}$ ). This corresponds to a 34.18 and $40.17 \%$ time reduction, respectively (Figure 4 ).
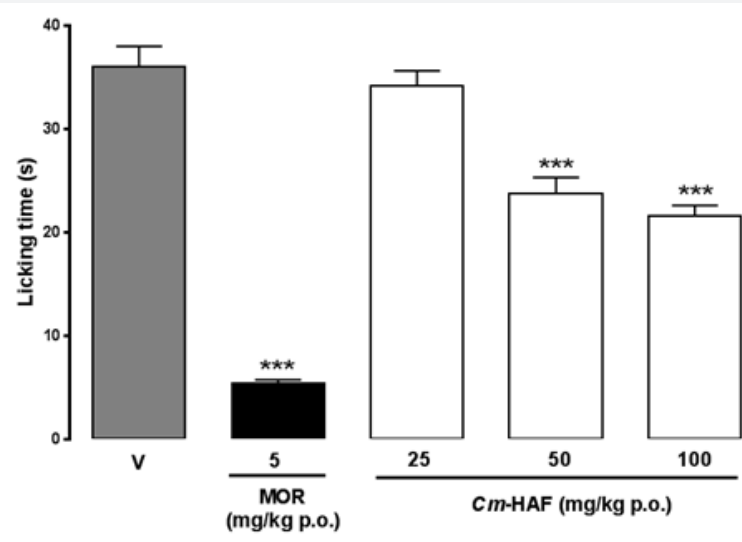

Figure 4: Antinociceptive effect of $\mathrm{Cm}$-HAF administered orally against capsaicin induced nociception in mice. Each column represents the mean \pm S.E.M of 7-12 animals. Control value (V) indicates animals treated with vehicle and the asterisks denote the significance levels, when compared with control groups (one-way ANOVA followed by Bonferroni test) $\left({ }^{* *} p<0.001\right)$.

\section{Glutamate Test}

Cm-HAF (12.5 and $25 \mathrm{mg} / \mathrm{kg}$ p.o.) significantly reduced the response time of the animals when compared with vehicle $(\mathrm{Cm}$ HAF 12.5 mg/kg: $63.23 \pm 4.50$ s; Cm-HAF 25 mg/kg: $60.40 \pm 5.47$ $\mathrm{s}$ and vehicle $92.72 \pm 3.04 \mathrm{~s}$ ). This corresponds to a 31.80 and $34.85 \%$ time reduction, respectively (Figure 5).

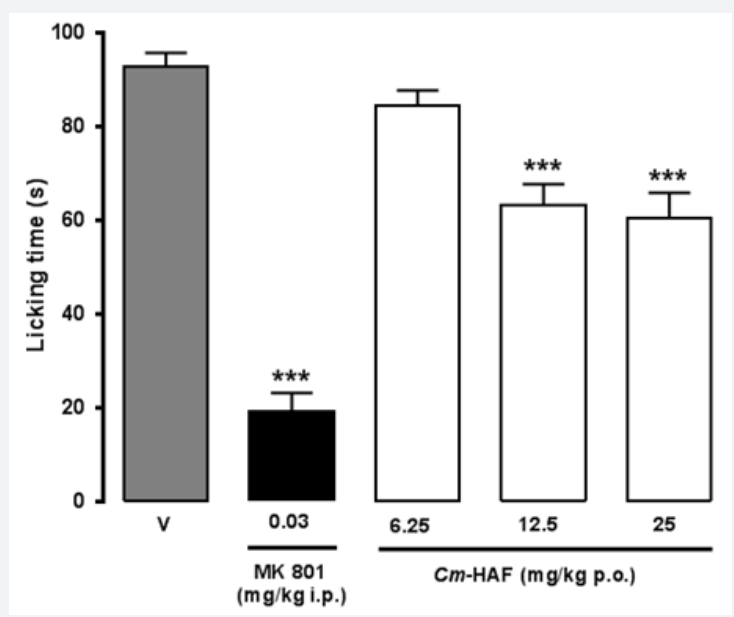

Figure 5: Antinociceptive effect of $\mathrm{Cm}$-HAF administered orally against glutamate-induced nociception in mice. Each column repre $\neg$ sents the mean \pm S.E.M. of $6-12$ animals. Control value (V) indicates the animals treated with vehicle and the asterisks denote the significance levels, when compared with control groups (one-way ANOVA followed by Bonferroni test) $\left(^{* *} p<\right.$ $0.001)$.

\section{Measurement of Locomotor Activity}

$\mathrm{Cm}$-HAF at dose of $100 \mathrm{mg} / \mathrm{kg}$ did not alter the number of crossed quadrants $(58.60 \pm 11.60)$ compared with vehicle $(73.85$ \pm 12.90 ). However, diazepam ( $4 \mathrm{mg} / \mathrm{kg}$ s.c.) significantly reduced locomotion in the open field $(11.16 \pm 2.61)$, representing an $84.92 \%$ time reduction. 
Experimental Model of Chronic Monoarthritis Induced by Complete Freund's Adjuvant

Paw edema. The group treated with vehicle showed an increase in the diameter of induced paw in the first hour after booster dose $\mathrm{D}(0)(0.45 \pm 0.04 \mathrm{~mm})$. The diameter reached its highest value at $\mathrm{D}(1)(1.70 \pm 0.13 \mathrm{~mm})$, plateaued until $\mathrm{D}(3)$ and progressively reduced until $\mathrm{D}(14)(0.79 \pm 0.08 \mathrm{~mm}) . \mathrm{Cm}$ HAF (50, 100 and $200 \mathrm{mg} / \mathrm{kg}$ p.o.) and IND (3 mg/kg p.o.) did not change paw diameter when compared with vehicle $\mathrm{D}(0-14)$. DEX (0.4 mg/kg p.o.) showed a reduction of the paw diameter at $\mathrm{D}(1)(1.21 \pm 0.06 \mathrm{~mm})$, corresponding to a $28.80 \%$ inhibition when compared with vehicle and remained the same until D(14) (103.79\%) (Figure 6).

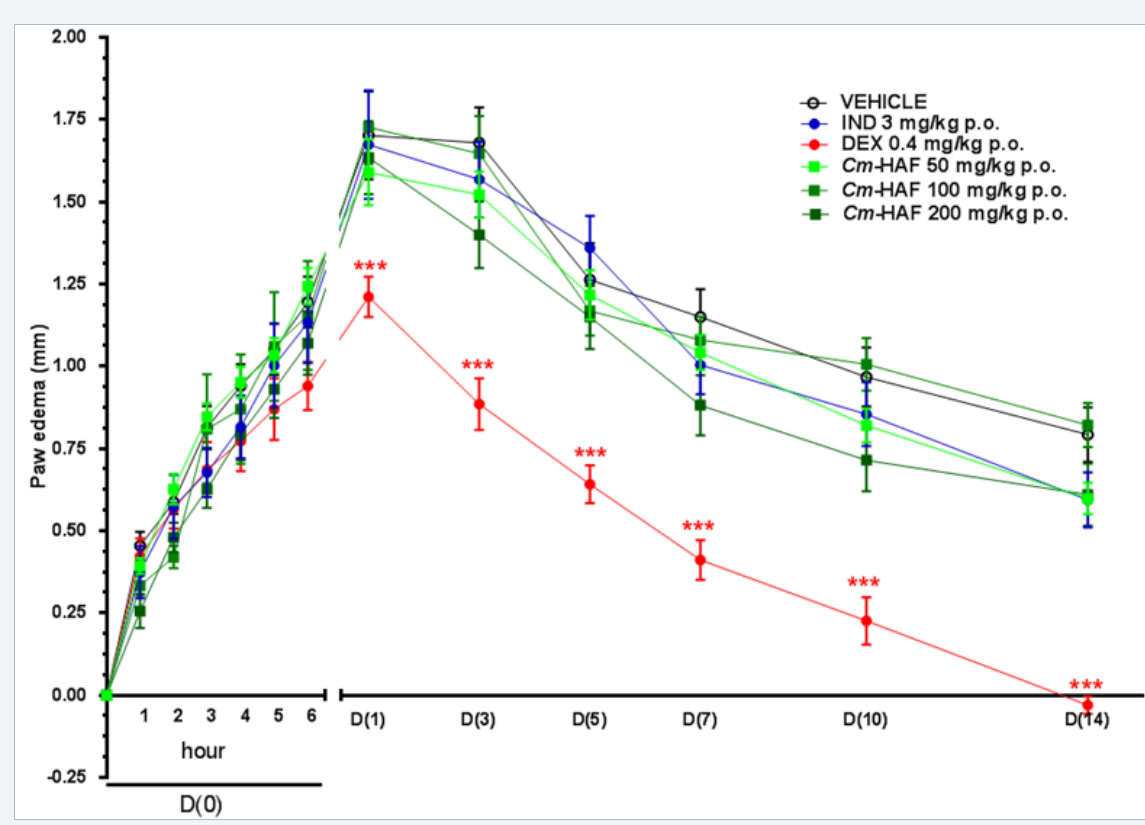

Figure 6: Acute $D(0-1)$, sub-acute $D(3-7)$ and chronic $D(10-14)$ antiedematogenic effect of $C m$-HAF administered orally against CFAinduced monoarthritis in rats. Data are expressed as mean \pm S.E.M. of 6-9 animals. Control value $(\mathrm{V})$ indicates the animals treated with vehicle and the asterisks denote the significance levels, when compared with control group $\left({ }^{*} p<0.05,{ }^{* *} p<0.01,{ }^{* * *} p<0.001\right)$ (two-way ANOVA followed by Bonferroni test).

\section{Histological Evaluation}

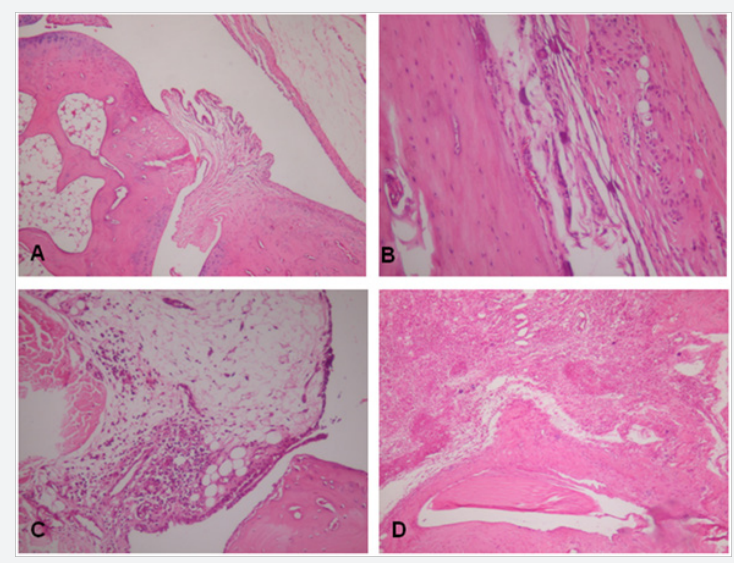

Figure 7: Histology of tibio-tarsal joints from CFA-induced monoarthritic treated, nontreated, and normal rats (haematoxylin and eosin staining).
A. Left hind paw/vehicle (negative control)(Score zero);
B. Right hind paw/DEX (0.4 mg/kg p.o.)(Score 1);
C. Right hind paw/Cm-HAF (100 mg/kg p.o.)(Score 2);
D. Right hind paw/vehicle (Score 3). Histological grading of lesions: 0 (normal), 1 (mild changes), 2 (moderate changes) and 3 (severe changes) (optical microscopy $(100 x)$ ). 
After 15 days D(0-14) of treatment with $\mathrm{Cm}$-HAF (50, 100 and $200 \mathrm{mg} / \mathrm{kg}$ p.o.), CFA-induced monoarthritic rat's paws showed no significant histological differences when compared with vehicle group (median 2, 2.83, 3 and 3), respectively. Groups treated with IND ( $3 \mathrm{mg} / \mathrm{kg}$ p.o.) and DEX (0.4 mg/kg p.o.) showed similar results (Figure 7).

\section{Mechanical Hyperalgesia (Randall-Sellito's Modified Test)}

The vehicle (negative control) group showed a lower withdrawal threshold during the first hour after induction (5.27 $\pm 0.26 \mathrm{~g}$ ) when compared with the initial threshold (before induction) $(5.83 \pm 0.14 \mathrm{~g})$. The threshold decreased until the $5^{\text {th }}$ hour (3.94 $\pm 0.27 \mathrm{~g})$, then increased until the $\mathrm{D}(5)$ ( $4.44 \pm 0.13$ g) and decreased again until D (14), when it reached its lowest value (3.94 $\pm 0.15 \mathrm{~g}$ ). $\mathrm{Cm}$-HAF (50 mg/kg p.o.) had no significant effect on withdrawal threshold in any phase. Cm-HAF (100 mg/ $\mathrm{kg}$ p.o.) significantly increased the withdrawal threshold as early as the $3^{\text {rd }}$ hour after induction $(5.75 \pm 0.11 \mathrm{~g})$ compared with the vehicle $(4.44 \pm 0.21 \mathrm{~g}$ ), representing a $29.50 \%$ increase. $\mathrm{Cm}$ HAF (100 mg/kg p.o.) showed a maximum withdrawal threshold increase at the $5^{\text {th }}$ hour after induction (5.66 \pm 0.10 and vehicle: $3.94 \pm 0.27 \mathrm{~g}$ ), corresponding to a $43.65 \%$ increase. $\mathrm{Cm}$-HAF (200 $\mathrm{mg} / \mathrm{kg}$ p.o.) increased withdrawal threshold at the $2^{\text {nd }}$ hour after induction ( $5.57 \pm 0.20$ and vehicle: $4.94 \pm 0.19 \mathrm{~g}$ ), corresponding to an $18.42 \%$ increase.

The greatest increase in the withdrawal threshold with $\mathrm{Cm}$ HAF (200 mg/kg p.o.) compared with vehicle was at $5^{\text {th }}$ hour after induction (5.64 \pm 0.14 and $3.94 \pm 0.27 \mathrm{~g}$, respectively), corresponding a $43.18 \%$ increase. IND ( $3 \mathrm{mg} / \mathrm{kg}$ p.o.) has also showed a withdrawal threshold increase at the $2^{\text {nd }}$ hour after induction (5.78 \pm 0.10 and vehicle: $4.94 \pm 0.19 \mathrm{~g})$, corresponding to a $17.00 \%$ increase. The withdrawal threshold peak in IND ( $3 \mathrm{mg} / \mathrm{kg}$ p.o.) occurred at the end of the chronic phase D (14) (5.84 \pm 0.09 and vehicle: $3.94 \pm 0.15 \mathrm{~g}$ ), representing a $48.47 \%$ increase. DEX (0.4 mg/kg p.o.) increased in the withdrawal threshold as late as at the $D(7)$ (5.43 \pm 0.14 , vehicle: $4.27 \pm 0.14$ g), representing a $27.16 \%$ increase. The withdrawal threshold peak with DEX (0.4 mg/kg p.o.) was reached at D (14) (5.50 \pm 0.13 and vehicle: $3.94 \pm 015 \mathrm{~g}$ ), with a $39.59 \%$ increase. $\mathrm{Cm}$-HAF (100 and $200 \mathrm{mg} / \mathrm{kg}$ p.o.) and IND (3 mg/kg p.o.) had a similar effect, but $\mathrm{Cm}$-HAF (200 mg/kg p.o) had a quicker effect than Cm-HAF (100 mg/kg p.o.). At D(14), Cm-HAF (100 mg/kg p.o.) also showed a smaller increased withdrawal threshold when compared with IND ( $3 \mathrm{mg} / \mathrm{kg}$ p.o.) $(5.00 \pm 0.12$ and $5.85 \pm 0.09$ g) (Figure 8).

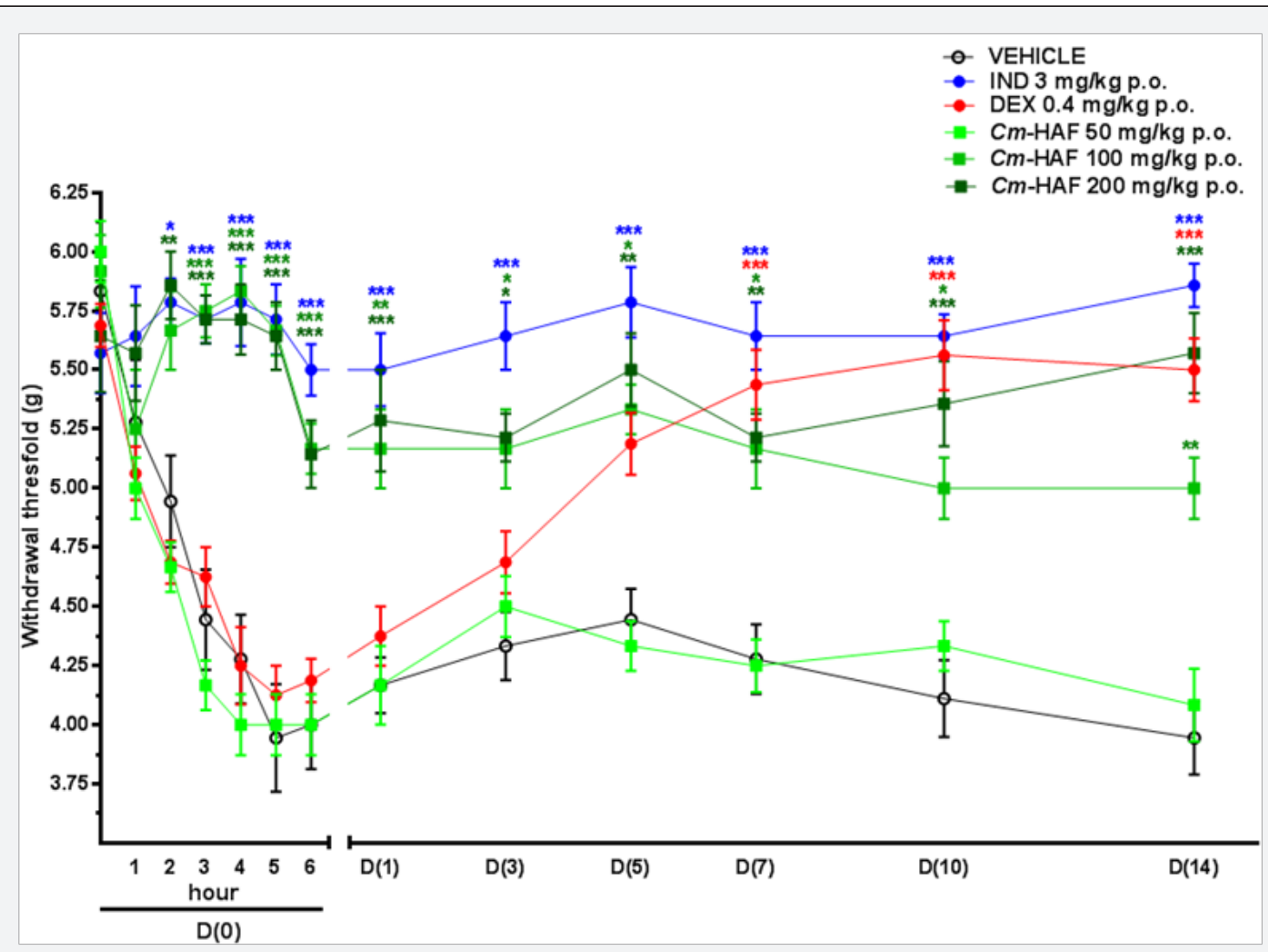

Figure 8: Acute $\mathrm{D}(0-1)$, sub-acute $\mathrm{D}(3-7)$ and chronic $\mathrm{D}(10-14)$ antinociceptive effect of $C m$-HAF administered orally against CFA-induced monoarthritis in rats. Data are expressed as mean \pm S.E.M. of 6-9 animals. Control value $(V)$ indicates the animals treated with vehicle and the asterisks denote the significance levels, when compared with control group $\left.{ }^{* * *} p<0.001\right)$ (two-way ANOVA followed by Bonferroni test). 
Effect of $\mathrm{Cm}$-HAF treatment in BUN, creatinine, ALT, total body weight, wet weight of kidneys and liver and macroscopical evaluation of gastric mucosae. Chronic treatment of CFA-induced monoarthritic rats with $\mathrm{Cm}$-HAF (50, 100 e $200 \mathrm{mg} / \mathrm{kg}$ p.o.) for 15 days $(\mathrm{D}(0-14))$ showed no difference in kidney function (BUN and creatinine), ALT, total body weight, wet weight of kidneys/liver and macroscopical evaluation of gastric mucosae when compared with vehicle.

\section{Discussion}

This study assessed the pharmacological activity of hydroalcoholic fraction from Cenostigma macrophyllum Tul. var. acuminata Teles Freire (Leguminosae) leaves ( $\mathrm{Cm}-\mathrm{HAF})$ in experimental models of nociception and inflammation, as well as in a chronic monoarthritis model (CFA-induced monoarthritis in rats). $\mathrm{Cm}$-HAF showed an antinociceptive effect against acute chemical nociceptive models in mice (formalin, capsaicin and glutamate tests) and a marked antinociceptive effect on acute, sub-acute and chronic inflammatory nociceptive pain in CFAinduced monoarthritis model in rats.

Cenostigma macrophyllum Tul. var. acuminata Teles Freire has been studied in the Department of Chemistry and Center for Research on Medicinal Plants (NPPM) UFPI. HPLC analysis of $\mathrm{Cm}$-HAF with co-injection of authentic standard showed the presence of two biflavones as the main constituents: agathisflavone and amentoflavone. No acute toxic effects for oral use of $\mathrm{Cm}$-FHA were founds in a study Viana et al. [8]. Another study for the evaluation of sub-acute (30 days) and semi-chronic (90 days) toxicity of aqueous ( $\mathrm{Cm}$-Aq) and $\mathrm{Cm}$-E.EtOH in rats of both sexes showed no significant subacute toxicity, but showed a semi-chronic increase in liver weights without alterations of seric bilirubin or albumin on rats (unpublished results). These findings indicate a safety profile for the orally therapeutic use of $\mathrm{Cm}$-HAF.

We started the investigation of the antinociceptive activity of $\mathrm{Cm}$-HAF using formalin induced nociception in mice. This model of inflammatory pain has two distinctive phases which may indicate different types of pain and be useful not only for assessing the analgesic substances, but also for elucidating its mechanism of analgesia. The initial phase (0-5 min) or neurogenic pain is caused by direct chemical stimulation promoted by formalin on nociceptors, in type $\mathrm{C}$ and part of the A $\delta$ afferent fibers and reflects centrally-mediated pain. It is associated with the release of excitatory amino acids, such as nitric oxide (NO) and substance P (SP). The second phase (15-30 min) or inflammatory pain is related to local release of chemical mediators such as histamine, serotonin, bradykinin, prostaglandins and excitatory amino acids Hunskaar \& Hole [12]; Tjølsen et al. [13]; Corrêa \& Calixto [22].

$\mathrm{Cm}$-HAF orally given significantly reduced nociception only in the late phase of the test without dose-dependency. Although we did not find effect of $\mathrm{Cm}$-HAF in the first phase of the formalin test and since formalin-induced pain involves numerous mediators, channels, and receptors as well as nerve fiber types and signaling pathways on both phases Salat \& Filipek [23], we decided to use other more specific tests to evaluate neurogenic pain. $\mathrm{Cm}$-HAF inhibited the neurogenic nociception caused by intraplantar injection of capsaicin; an alkaloid extracted from red pepper Capsicum which stimulates nerve endings eliciting an intense thermal and nociceptive pain Sakurada et al. [14]; Santos \& Calixto [15]; Binotti et al. [24]. This suggests an antagonistic action on peripherals or central vanilloid receptors.

Capsaicin acts on vanilloid receptors (TRPV-1) in the peripheral nervous system by opening a non-selective cation channel, which allows the influx of cations, especially $\mathrm{Ca}^{2+}$ and $\mathrm{Na}^{+}$, depolarizes the cell membrane and triggers the action potential. TRPV-1 receptors can be activated if temperature is above $43{ }^{\circ} \mathrm{C}$, a similar temperature condition to that which causes pain Binotti et al. [24]; Okuse [25]; Palazzo et al. [26].

Capsaicin causes depolarization of dorsal root ganglion cells associated with type $\mathrm{C}$ demyelinated fibers and probably also with A $\delta$ myelinated fibers, without affecting other sensory neurons, and promotes the release of several neuropeptides, especially tachykinins (SP, neurokinin A and neurokinin B), which act in the transmission of pain and nociceptive pathways in inflammatory processes Binotti et al. [24]; Sakurada et al. [14], Santos \& Calixto [15]. It has been reported that some flavonoids, such as eriodictyol, can inhibit the binding of a known modulator to the TRPV-1 receptor and inhibited the calcium influx mediated by capsaicin. It also had an antinociceptive effect in the intraplantar capsaicin tests and antihyperalgesic and anti-allodynic effects in the CFA test Rossato et al. [27]. These findings suggest that the analgesic effect of $\mathrm{Cm}$-HAF in capsaicin test and CFA-induced arthritis might be related to the presence of flavonoids.

Furthermore, $\mathrm{Cm}$-HAF exhibited significant activity when the glutamate model was used. Glutamate is the main excitatory neurotransmitter involved in nociceptive signal transmission through primary afferent fibers, as well as in the development and maintenance of the pain response Beirith et al. [16]. Moreover, the intraplantar injection of glutamate releases excitatory aminoacids, prostaglandin E2 $\left(\mathrm{PGE}_{2}\right)$, NO, kinins, protons, SP and more glutamate in the dorsal horn. Glutamate induces a nociceptive response through its action on glutamate receptors that are present in periph $\urcorner$ eral, spinal and supraspinal sites of action and is largely mediated by both NMDA (N-methylD-aspartate) and non-NMDA receptors and by release of NO or by some NO-related substance Beirith et al. [16]; Sakurada et al. [14]. Thus, it is suggested that the constituents of $\mathrm{Cm}-\mathrm{HAF}$, such amenthoflavone itself could interfere with the activation of NMDA receptors, which would limit the production of NO and other mediators Beirith et al. [16]; Araújo et al. [28].

Drugs with sedative activity can also inhibit motor response Watanabe et al. [29]. Cm-HAF did not reduce the animals' 
spontaneous locomotor activity in the open-field test with the highest doses that presented antinociceptive effect Silva et al. [30]. This suggests that the sedative action of $\mathrm{Cm}$-HAF may not be involved in the antinociceptive activity. Considering our group previous results (unpublished results) and the inhibitory properties of $\mathrm{Cm}$-HAF on the late phase of formalin, it is possible that its antinociceptive activity is due, at least in part, to an antiinflammatory action. Thus, we decided to evaluate $\mathrm{Cm}$-HAF antiinflammatory/arthritic properties.

CFA-induced arthritis has been often used as a model for human rheumatoid arthritis and was originally described as a polyarthritic model Pearson [31]. It has been modified to limit the inflammatory process to a single joint (monoarthritis) in an attempt to cause a less intense arthritis, thus avoiding the severe discomfort, stress on the animals, altered weight gain and systemic disease. Most modifications have involved the local injection of CFA either into Butler et al. [32] or around the tibiotarsal joint Donaldson et al. [33]; Gomes [19]. We chose the last route of administration as the most appropriate in our study. Histologically, arthritis generated in this model is less severe than in classical polyarthritis, but still shows many of the features of rheumatoid arthritis such as pannus formation, without no findings or lesions of severe disease such as joint ankylosis Donaldson et al. [33].

Our results demonstrate that CFA-induced monoarthritis in female Wistar rats is a suitable model for evaluating inflammatory pain and rat paw edema (animals developed full blown arthritis at $100 \%$ incidence reproducibly). Nociceptive withdrawal thresholds to mechanical stimulation (mechanical allodynia) were measured using Randall-Sellito's modified test. Rats showed a significant allodynia one hour after CFA's booster injection $(D(0))$, which persisted while inflammation was apparent D(14). Cm-HAF antinociceptive action was similar to indomethacin, a potent non-steroidal anti-inflammatory drug. This is in agreement with $\mathrm{Cm}$-HAF antinociceptive effect in late phase of formalin test (inflammatory phase). Moreover, $\mathrm{Cm}$-HAF showed no common adverse effects related to the use of non-steroidal anti-inflammatory drugs (NSAID), such as the macroscopic gastric lesions, hepatotoxicity and nephrotoxicity (BUN, creatinine, ALT, wet weight of kidneys and liver). The weights of the adult rats remained unchanged over the period of study with no significant differences between CFA-induced monoarthritis and the control groups, or when compared with pre-induction values.

On the other hand, $\mathrm{Cm}$-HAF and indomethacin showed a similar antinociceptive but no antiedematogenic effect against CFA-induced monoarthritis. The lack of antiedematogenic effect of $\mathrm{Cm}$-HAF and indomethacin may be due the well known ability of NSAID drugs to provide pain relief with a smaller dosis than necessary for an anti-inflammatory effect Bradley [34]. Dexamethasone showed a potent antiedematogenic action, but the decrease in paw diameter in part could be due to a significant weight loss. Higher $\mathrm{Cm}$-HAF dosis and/or alternative routes (such as i.p.) demands further evaluation. Histological analysis showed that there was no inflammation present in some contra lateral joints and no difference in induced paw in any treatment group when compared with the control.

Agathisflavone and amentoflavone were found as the main Cm-HAF constituents. These biflavonoids have been shown to have biological and pharmacological properties such as antibacterial, antifungal, antiviral, hepatoprotective, inhibition of histamine release from mast cells and inhibition of lymphocyte proliferation, suggesting the anti-inflammatory/ antiallergic potential effects of the biflavonoids Kim et al. [9]. Amentoflavone was also found to inhibit cyclooxygenase (COX). It showed a potent anti-inflammatory activity as determined by amelioration of croton-oil induced mouse ear edema and paw oedema induced by carrageenan (ED50 $=42 \mathrm{mg} / \mathrm{kg}$ ) similar to the activity of prednisolone (35 mg/kg) and IND (10 mg/kg).

In addition, it was found to possess a potent analgesic activity in the acetic acid writhing test (ED50 $=9.6 \mathrm{mg} / \mathrm{kg}$ ) similar to the activity of IND (3.8 mg/kg) Kim et al. [35]. Amentoflavone inhibits the lipopolysaccharide (LPS)-induced production of NO in macrophages by blocking NF-kB activation Woo \& cols [36], suppresses the production of $\mathrm{NO}$ and $\mathrm{PGE}_{2}$ in RAW264.7 cells stimulated with the TLR4 ligand LPS and also inhibits the formation of a molecular complex including extracellular signalregulated kinase (ERK) and c-Fos (a subunit of activator protein (AP)-1) Oh et al. [37]. There is no available data about antiinflammatory action of agathisflavone. Flavonoid bioavailability is reportedly very low in mammals Passamonti et al. [38], which implies the need for further research with other routes of administration.

In summary, our results demonstrate that $\mathrm{Cm}$-HAF exhibited antinociceptive action in animal models of acute chemicalinduced pain. $\mathrm{Cm}$-HAF also showed antinociceptive effect against inflammatory pain in modified CFA-induced monoarthritis in rats, which showed to be a suitable model for evaluation of acute, subacute and chronic nociception. So, the multiple possible mechanisms of this vegetable preparation are opportunities to develop drugs that will provide relief of pain. The results confirm the popular use of this plant as a painkiller, and contribute to the pharmacological knowledge of this species.

\section{Conflict of Interest}

The authors declare that they do not have any financial conflict of interests.

\section{References}

1. Silman AJ (2001) Rheumatoid arthritis. In: Silman AJ, Hochberg MC, editors. Epidemiology of the Rheumatic Diseases. ( $2^{\text {nd }}$ edn), Oxford University Press, New York, USA, p. 31-71.

2. Feist E, Burmester GR (2013) Small molecules targeting JAKs - a new approach in the treatment of rheumatoid arthritis. Rheumatology (Oxford) 52(8): 1352-1357. 
3. Lewis A, Levy A (2011) Anti-inflammatory activities of Cassia alata leaf extract in complete Freund's adjuvant arthritis in rats. West Indian Med J 60(6): 615-621.

4. Norn S, Permin H, Kruse PR, Kruse E (2009) From willow bark to acetylsalicylic acid. Dan Medicinhist Arbog 37: 79-98.

5. Queiroz LP (2009) Legumes of the Caatinga. Royal Botanic Garden, Edinburg, USA.

6. Ribeiro RC, Pelacani CR (2006) Effect of manitol and $\mathrm{NaCl}$ on the germination of seeds of two leguminous species with importance to the Bahian dryland. Sitientibus 6:105-109.

7. Sousa CMM, Silva HR, Vieira-Jr GM, Ayres MCC, Costa, CLS, et al. (2007) Total phenolics and antioxidant activity of five medicinal plants. Quim Nova, São Paulo 30: 351-355.

8. Viana AF, Fernandes HB, Silva FV, Oliveira IS, Freitas FFBP (2013) Gastroprotective activity of Cenostigma macrophyllum Tul. var. acuminata Teles Freire leaves on experimental ulcer models. Ethnopharmacol 150: 316-323.

9. Kim HP, Park H, Son KH, Chang HW, Kang SS, et al. (2008) Biochemical Pharmacology of Biflavonoids: implications for anti-inflammatory action. Arch Pharm Res 31(3): 265-273.

10. Southon IW, Bisby FA, Buckingham J, Harborne JB (1994) Phytochemical dictionary of the Leguminosae. Chapman and Hall, London, UK.

11. Piaulino CA, Carvalho FCB, Almeida BC, Chaves MH, Almeida FRC, et al. (2013) The stem bark extracts of Cenostigma macrophyllum attenuates tactile allodynia in streptozotocin-induced diabetic rats. Pharm Biol 51: $1243-1248$

12. Hunskaar S, Hole K (1987) The formalin test in mice: dissociation between inflammatory and non-inflammatory pain. Pain 30(1): 103114

13. Tjølsen A, Berge OG, Hunskaar S, Rosland JH, Hole K (1992) The formalin test: an evaluation of the method. Pain 51: 5-17.

14. Sakurada T, Katsumata K, Tanno K, Sakurada S, Kisara K (1992) The capsaicin test in mice for evaluating tachykinin antagonists in the spinal cord. Neuropharmacology 31(2): 1279-1285.

15. Santos ARS, Calixto JB (1997) Further evidence for the involvement of tachykinin receptor subtypes in formalin and capsaicin models of pain in mice. Neuropeptides 31(4): 381-389.

16. Beirith A, Santos ARS, Calixto JB (2002) Mechanisms underlying the nociception and paw oedema caused by injection of glutamate into the mouse paw. Brain Res 924(2): 219-228.

17. Broadhurst PL (1957) Determinations of emotionality in the rat: I situation factors. Br J Psychol 48(1): 1-12.

18. Randall LO, Selitto JJ (1957) A method for measurement of analgesic activity on inflamed tissue. Arch Int Pharmacodyn Ther 111: 409-419.

19. Gomes RP, Bressan E, Silva TM, Gevaerd Mda S, Tonussi CR, et al. (2014) Effects of one minute and ten minutes of walking activity in rats with arthritis induced by complete Freund's adjuvant on pain and edema symptoms. Rev Bras Reumatol 54(2): 83-89.

20. Beehler BC, Hei YJ, Chen S, Lupisella JA, Ostrowski J, et al. (2003) Inhibition of disease progression by a novel retinoid antagonist in animal models of arthritis. J Rheumatol 30(2): 355-363.

21. Szabo S, Trier JS, Brown A, Schnoor J (1985) Early vascular injury and increased vascular permeability in gastric mucosal injury caused by ethanol in the rat. Gastroenterology 88: 228-236.
22. Corrêa CR, Calixto JB (1993) Evidence for participation of B1 and B2 kinin receptor in formalin-induced nociceptive response in mouse. Brit J Pharmacol 110(1): 193-198.

23. Salat K, Filipek B (2015) Antinociceptive activity of transient TRPV1, TRPA1, and TRPM8 antagonists in neurogenic and neuropathic pain models in mice. J Zhejiang Univ Sci B 16(3): 167-178.

24. Binotti RS, Melo AMT, Oliveira C.H, De Nucci G (2003) Pimentavermelha (Capsicum fructescens - Solanaceae). Jornal Brasileiro de Fitomedicina 1: 6-11.

25. Okuse K (2007) Pain signaling pathways: from cytokines to ion channels. Int J Biochem Cell Bio 39(3): 490-496.

26. Palazzo E, Ross F, Maione S (2008) Role of TRPV1 receptors in descending modulation of pain. Mol Cell Endocrinol 286(1-2): 79-83.

27. Rossato MF, Trevisan G, Walker CIB, Klafke JZ, de Oliveira AP, et al. (2011) Eriodictyol: A flavonoid antagonist of the TRPV1 receptor with antioxidant activity. Biochem Pharmacol 81(4): 544-551.

28. Araújo AM, Montenegro FC, Mafra RA, Alves ARA, Oliveira FA, et al. (2006) Principais Sistemas de Neurotransmissão. In: Oliveira RN (edn), Psicofarmacologia - Fundamentos Práticos. Guanabara Koogan, Rio de Janeiro, pp 22-45.

29. Watanabe C, Satoh T, Tahara E, Murakami K, Hayashi K, et al. (1999) Inhibitory mechanism of glycoprotein fraction derived from Miscanthus sinensis for the immediate phase response of an IgEmediated cutaneous reaction. Biol Pharm Bull 22(1): 26-30.

30. Silva LL, Gomes BS, Sousa-Neto BP, Oliveira JPC, Ferreira ELF, et al. (2012) Effects of Lecythis pisonis Camb. (Lecythidaceae) in a mouse model of pruritus. J Ethnopharmacol 139(1): 90-97.

31. Pearson CM (1956) Development of arthritis, periarthritis and periostitis in rats given adjuvants. Proc Soc Exp Biol Med 91(1): 95101.

32. Butler SH, Godefroy F, Besson JM, Weil-Fugazza J (1992) A limited arthritic model for chronic pain studies in the rat. Pain 48(1): 73-81.

33. Donaldson LF, Seckl JR, McQueen DS (1993) A discrete adjuvantinduced monoarthritis in the rat: effects of adjuvant dose. J Neurosci Methods 49(1-2): 5-10.

34. Bradley JD, Brandt KD, Katz BP, Kalasinski LA, Ryan SI, et al. (1991) Comparison of an anti-inflammatory dose of ibuprofen, an analgesic dose of Ibuprofen, and acetaminophen in the treatment of patients with osteoarthritis of the knee. N Engl J Med 325(2): 87-91.

35. Kim HK, Son KH, Chang HW, Kang SS, Kim HP, et al. (1998) Amentoflavone, a plant bioflavone: a new potential anti-inflammatory agent. Arch Pharm Res 21(4): 406-410.

36. Woo ER, Lee JY, Cho IJ, Kim SG, Kang KW, et al. (2005) Amentoflavone inhibits the induction of nitric oxide synthase by inhibiting NF- $k \mathrm{~B}$ activation in macrophages. Pharmacol Res 51: 539-546.

37. Oh J, Rho HS, Yang Y, Yoon JY, Lee J, et al. (2013) Extracellular signalregulated kinase is a direct target of the anti-inflammatory compound amentoflavone derived from Torreya nucifera. Mediat Inflamm 2013: $1-11$.

38. Passamonti S, Terdoslavich M, Franca R, Vanzo A, Tramer F, et al. (2009) Bioavailability of flavonoids: a review of their membrane transport and the function of bilitranslocase in animal and plant organisms. Curr Drug Metab 10(4): 369-394. 
This work is licensed under Creative Commons Attribution 4.0 License DOI: $10.19080 /$ OROAJ.2017.08.555733

\section{Your next submission with Juniper Publishers} will reach you the below assets

- Quality Editorial service

- Swift Peer Review

- Reprints availability

- E-prints Service

- Manuscript Podcast for convenient understanding

- Global attainment for your research

- Manuscript accessibility in different formats

( Pdf, E-pub, Full Text, Audio)

- Unceasing customer service

Track the below URL for one-step submission https://juniperpublishers.com/online-submission.php 